\title{
Correction to: Recent approaches on the genomic analysis of the phytopathogenic fungus Colletotrichum spp.
}

\author{
María Carbú · Javier Moraga · Jesús M. Cantoral • Isidro G. Collado @ \\ Carlos Garrido
}
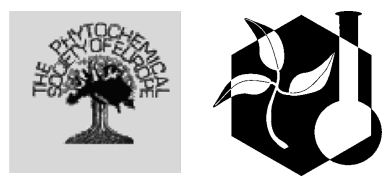

Published online: 17 October 2020

(C) Springer Nature B.V. 2020

\section{Correction to: \\ Phytochem Rev (2020) 19:589-601 \\ https://doi.org/10.1007/s11101-019-09608-0}

The authors wish to make it known that we mistakenly used some unpublished data from the Joint Genome Institute (JGI) database in some parts of this article in a way that violates the JGI usage agreement. We apologize to the principal investigators of the JGI Community Sequencing Projects (below) for this error.

- Genomic signatures of pathogenicity and endophytism in five species of grass-associated Colletotrichum impacting the health and production of bioenergy feedstocks, agriculture and the environment. Ref: CSP-2012-729. http://genome.jgi.doe. gov/Gensignvironment/Gensignvironment.info. html

The original article can be found online at https:// doi.org/10.1007/s11101-019-09608-0.

\section{Carbú · J. M. Cantoral · C. Garrido $(\square)$}

Department of Biomedicine, Biotechnology and Public Health, Laboratory of Microbiology, Faculty of Marine and Environmental Sciences, University of Cádiz,

11510 Puerto Real, Spain

e-mail: carlos.garrido@uca.es

\section{J. Moraga · I. G. Collado ( $\varangle)$}

Department of Organic Chemistry, Faculty of Sciences, University of Cádiz, 11510 Puerto Real, Spain

e-mail: isidro.gonzalez@uca.es
- Evolution and adaptation of carbohydrate utilization in the Colletotrichum acutatum species complex. Ref: CSP-2015-1661. https://genome.jgi.doe. gov/portal/Evoandspecomplex/

Evoandspecomplex.info.html

Additionally, Table 1 in the original version of this article unfortunately contained some errors. The corrected table is presented below (Table 1). 


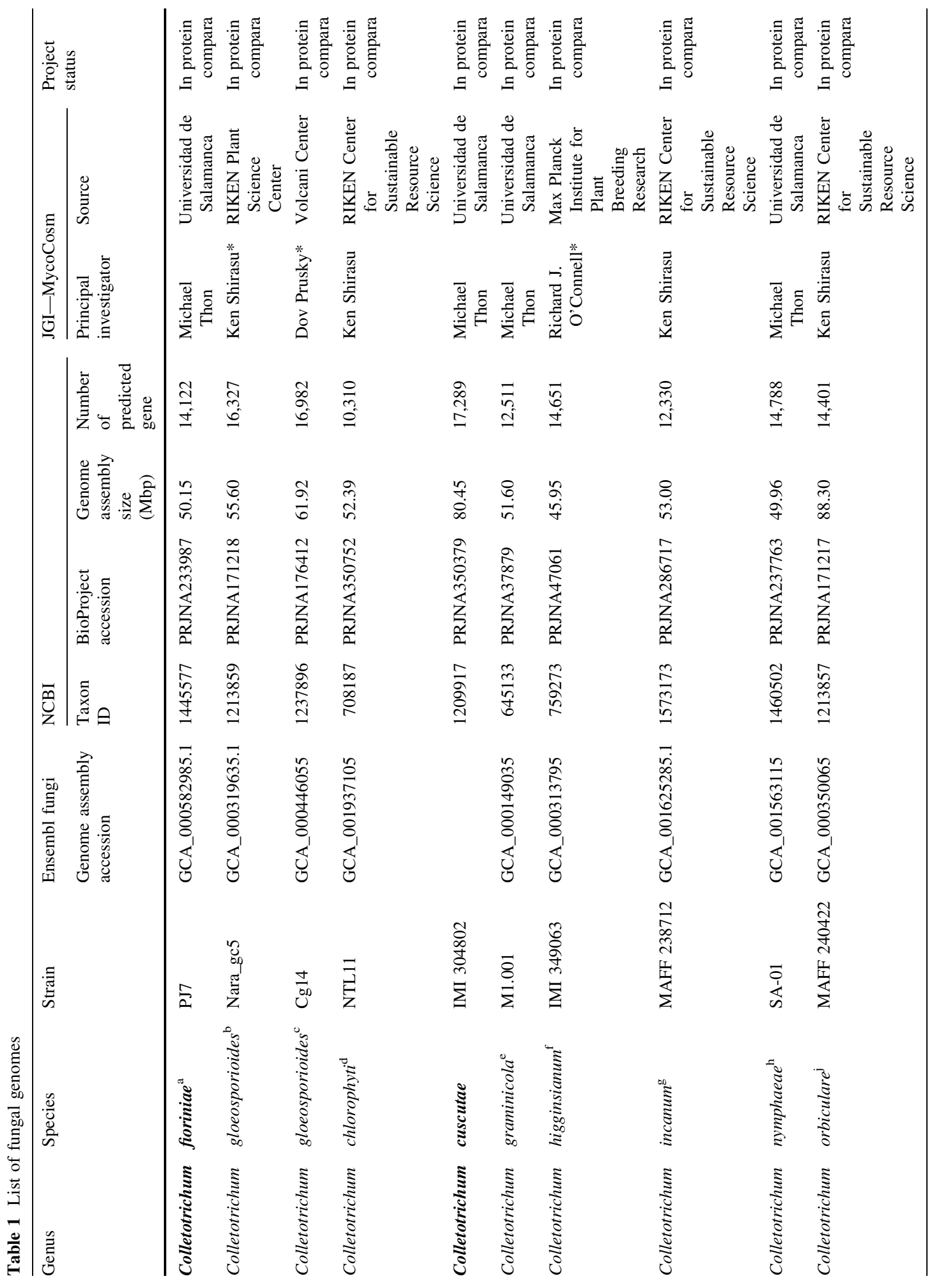




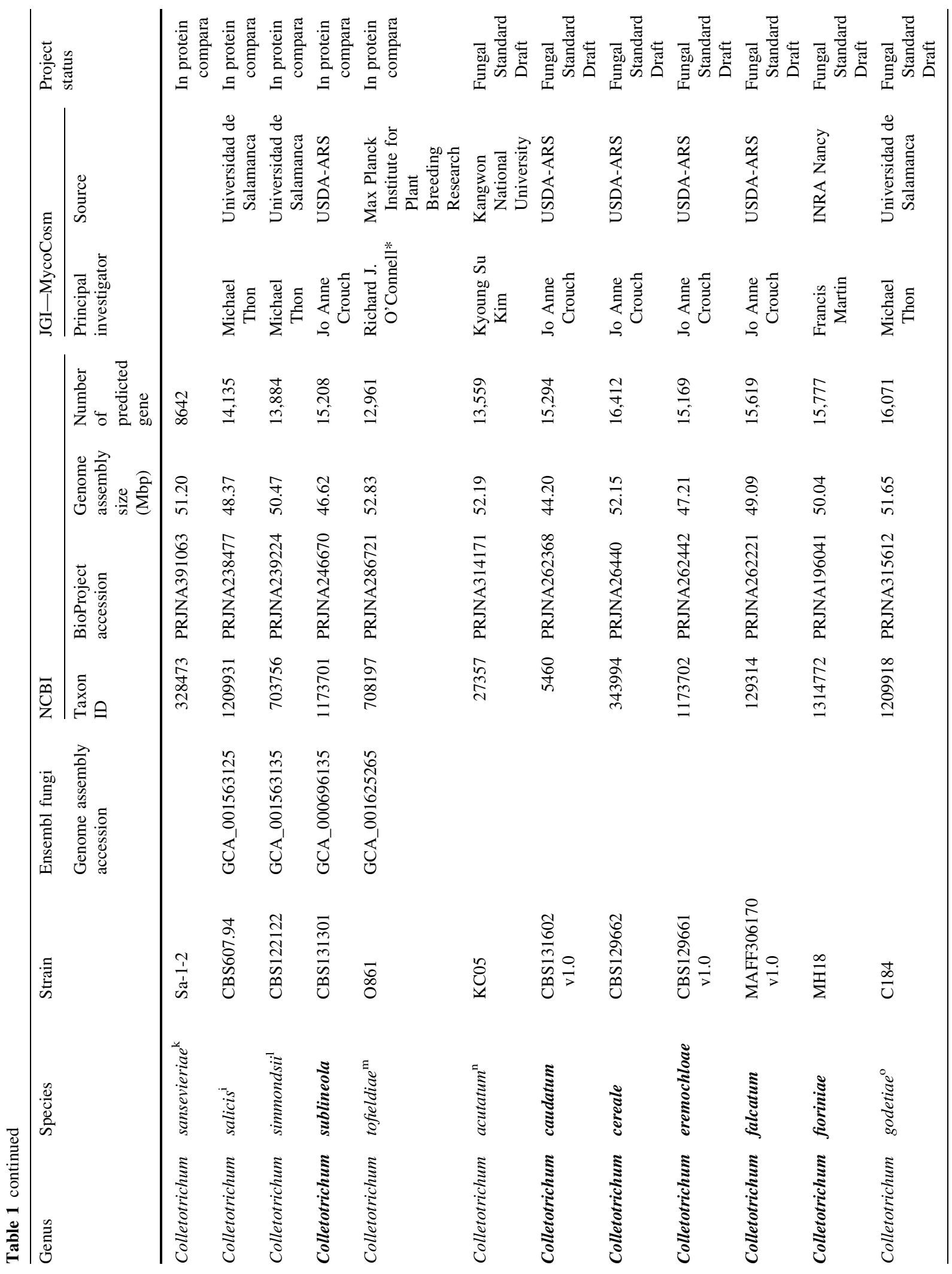




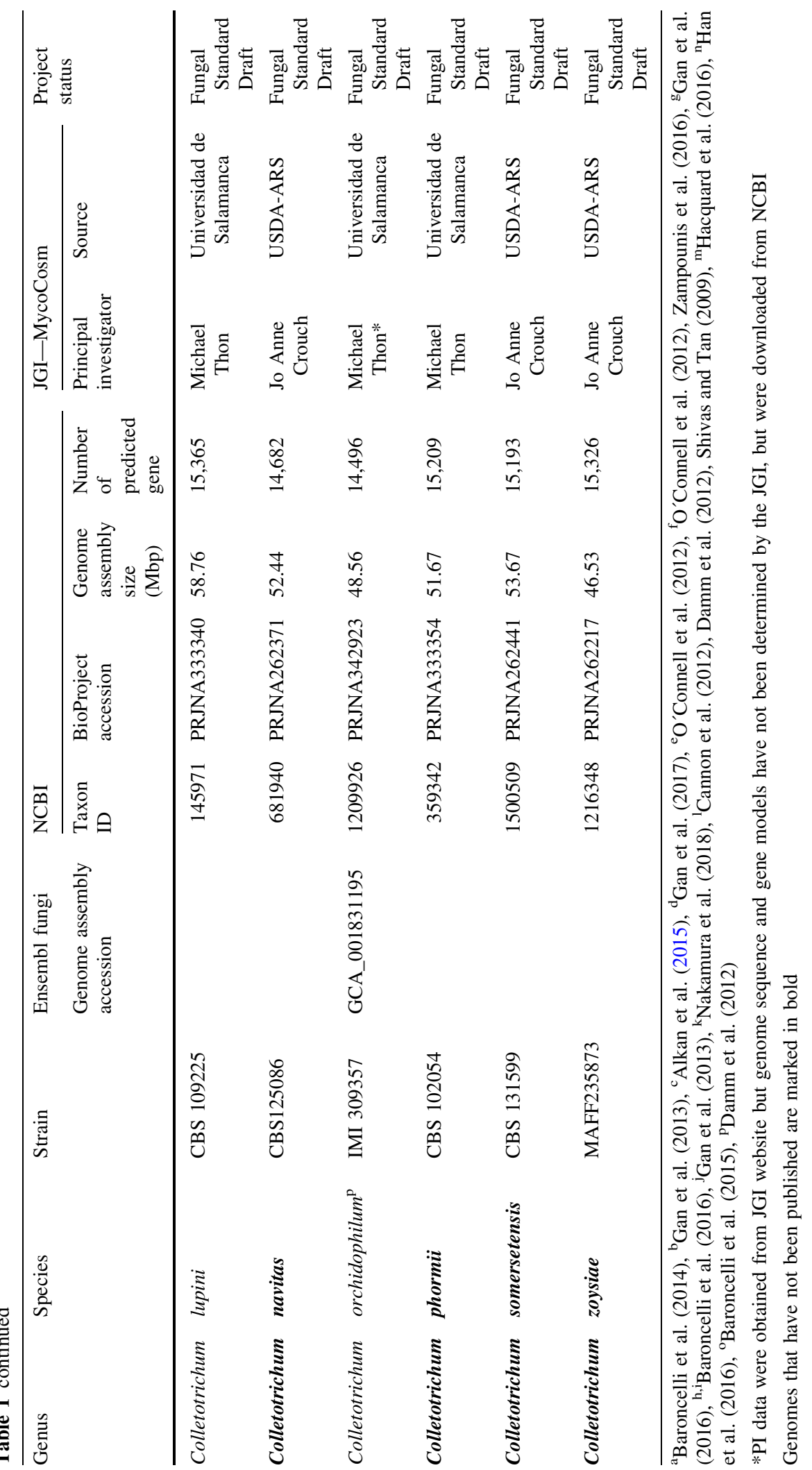




\section{Reference}

Alkan N, Friedlander G, Ment D, Prusky D, Fluhr R (2015) Simultaneous transcriptome analysis of Colletotrichum gloeosporioides and tomato fruit pathosystem reveals novel fungal pathogenicity and fruit defense strategies.
New Phytol 205:801-815. https://doi.org/10.1111/nph. 13087

Publisher's Note Springer Nature remains neutral with regard to jurisdictional claims in published maps and institutional affiliations. 